\title{
Workplace Bullying and Harassment among Health Care Professionals
}

\author{
SHEHLA CHANNA ${ }^{1}$, SAROSH KHAN ${ }^{2}$, ZAMIR HUSSAIN TUNIO ${ }^{3}$, RIZWAN ALI JHATIYAL ${ }^{4}$, IKRAM AHMED TUNIO ${ }^{5}$, \\ KHANWAD BUX UMRANI ${ }^{6}$ \\ ${ }^{1}$ Assistant Professorof Obstetrics \& Gynaecology, Liaquat University of Medical \& Health Sciences, Jamshoro \\ ${ }^{2}$ ST3 Locum Doctor, Western Health \& Social Care Trust Altnagelvin Hospital, Londonderry \\ ${ }^{3}$ Assistant Professor of Orthopedic Surgery \& Traumatology, Liaquat University of Medical \& Health Sciences, Jasmshoro \\ ${ }^{4}$ Consultant Orthopedic Surgeon, Liaquat University Hospital Hyderabad \\ ${ }^{5}$ Associate Professor of Forensic Medicine, Khairpur Medical College, Khairpur Mirs \\ ${ }^{6}$ Senior Registrar of Orthopedic Surgery \& Traumatology, Bolan University of Medical \& Health Sciences Quetta \\ Correspondence to Dr. Shehla Channa, E-mail: shehlaraza600@gmail.com, +923323630156
}

\begin{abstract}
Aim: To determine prevalence of workplace bullying and its effects on doctors at LUMHS Jamshoro.

Study design: Cross sectional survey.

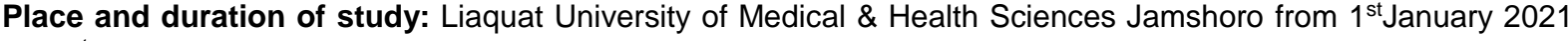
to $31^{\text {stMarch. }}$

Methodology:Seventy five postgraduate residents, house officers and medical officers were selected randomly, all were interviewed by questionnaire. Questions were asked regarding any incident of bullying, aggression, violence, and harassment during hospital duty hours. Which behavior they faced and what was the reason of that behavior; asked from participants. The data was entered and analyzed using the SPSS 22.

Results: Seventy four $(98.66 \%)$ were females and $1(1.33 \%)$ was male with mean age of $27.3 \pm 4.7$ years. 51 [68\%] have been subjected to being bullied. Main source of harassing was by administration in $12 \%$, faculty in $34.66 \%$, senior colleagues in $42.66 \%$ colleagues $16 \%$, paramedics $15 \%$, and patient's attendants in $13 \%$. Effects noticed on personality/ behavior were sadness in $41.33 \%$, aggression $32 \%$, confrontation change in sleep $12 \%$, health complaints in headache/ palpitations $34.66 \%$, loss of interest in activities $41.33 \%$, poor performance at work $18.66 \%$, lack of confidence $46.66 \%$, fear to go to work place $20 \%$ and avoiding bullier in $29.33 \%$.

Conclusion: Prevalence of bullying was $68 \%$ among health care professionals interviewed in this study. Violence towards medical caretakers is expanding day by day.Serving in safe and healthy surroundings is the basic right of every health care worker to take healthy decisions to give quality patient care.

Keywords: Bullying, harassment, Violence, Doctors, Heath care worker
\end{abstract}

\section{INTRODUCTION}

Bullying can be characterized as "tireless, hostile, harmful, scary, malevolent or offending conduct, maltreatment of force or ridiculous reformatory assents, which makes the recipient feel irritated, undermined, embarrassed or defenceless and subverts their self-assurance and may make them endure pressure. ${ }^{1}$ Harassing is an all-inclusive wonder that happens in different professions, and the medical profession is in no way, shape or form an exemption. There is proof that undergraduates, postgraduate trainee, experts, specialists undertaking research just as other medical services experts, including medical attendants as nursing staff, experience the ill effects of provocation or then again bullying ${ }^{2,3}$.

Work environment harassing is a huge issue because of its antagonistic effect on the wellbeing and well-being of influenced people. It has been related with undeniable degrees of occupation instigated pressure, tension, gloom, focus issues, uncertainty and absence of activity. Staff who have been tormented have additionally been found to have essentially lower levels of occupation fulfilment and are bound to have an aim to leave the job. Harassing has all the more as of late been related with the detailing of conceivably genuine clinical errors ${ }^{4-6}$.

Received on 01-04-2021

Accepted on 16-05-2021
Albeit harassing among health professionals has been concentrated broadly in the developed world, it has gotten little consideration in developing nations. Notwithstanding, there have been a few studies led in Pakistan that surveyed the degree of tormenting among subjects and alarmingly high rates of bullying have been reported in Pakistan ${ }^{3,7,8}$.

Medical care populace is confronting intense issues among them working environment brutality is one of the serious issues looked by wellbeing industry in terms of its extent and recurrence. Working environment brutality is a troubling circumstance all absurd and precise weight of this perilous circumstance isn't known on the grounds that considers are showing just a glimpse of something larger ${ }^{9,10}$.

Bullying of doctors is very serious issue globally and especially very prevalent in country like Pakistan where law and order situation is not in control. As doctors are front line workers and are being victimized to be bullying by everyone from patient, its attendant, seniors, faculty and administration. The quality of care of patient is related directly with the performance of health care workers. Ultimately qualitative patient care is our goal and to achieve this we have to provide safe, healthy friendly environment to our frontline workers. This study was intended to know about various aspects of bullying and its effects on doctors. 


\section{MATERIALS AND METHODS}

A cross-sectional survey was conducted at LUMHS

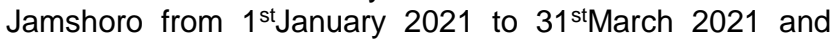
comprised 75 postgraduate residents, house officers and medical officers. Consent was taken from participants. The doctors were interviewed by questionnaire. The questionnaire was asked in order to encourage participation. It was administered and collected immediately upon completion by the data collection team. The primary part of the survey gathered segment data age, sexual orientation, schooling status soon of the doctors. Then next were asked regarding any incident of bullying, aggression, violence, and harassment during hospital duty hours. Which behavior they faced and what was the reason of that behavior; asked from participants. Questionnaire contained more questions regarding bullying and its social psychological effects. Participants were assured that none will know about your identity and no will recognize you so that actual data can be gathered. The data was entered and analyzed using the SPSS 22.

\section{RESULTS}

There were $74(98.66 \%)$ female and $01(1.33 \%)$ male with mean age of $27.3 \pm 4.7$ years. $20 \%$ were house officer, $61.33 \%$ were postgraduate residents and $18.66 \%$ were medical officers. 88\% were posted at Department of Gynecology and Obstetrics and $122 \%$ were related to other Departments. 51 [68\%] have been subjected to discriminate behavior by others which eroded their professional confidence or self-esteem. Main source of undermining or harassing was by administration in $12 \%$, faculty in $34.66 \%$, senior colleagues in $42.66 \%$ colleagues $16 \%$, paramedics $15 \%$, and patient's attendants in $13 \%$. $26 \%$ have complained anyone about that behavior while $53.33 \%$ didn't. The ways of discriminate behavior were mocking/ scoffing/ making hurtful comments in $42.66 \%$, discouragement on work done in $45.66 \%$, giving too much assignments/workload $22.66 \%$, exclusion from classes/practical work/ward rounds/ OT list in $18.66 \%$. Effects noticed on personality/ behavior were sadness in $41.33 \%$, aggression $32 \%$, confrontation change in sleep $12 \%$, health complaints in headache/ palpitations $34.66 \%$, loss of interest in activities $41.33 \%$, poor performance at work $18.66 \%$, lack of confidence $46.66 \%$, fear to go to work place $20 \%$ and avoiding bullier in $29.33 \%$ (Table 1 ).

Table 1: Descriptive statistics of participants who faced bullying behavior
\begin{tabular}{|l|c|c|}
\hline Variable & No. & $\%$ \\
\hline Gender & 1 & 1.33 \\
\hline Male & 74 & 98.66 \\
\hline Female & 24 & 32.0 \\
\hline Age (Years) & 40 & 53.33 \\
\hline $20-25$ & 8 & 10.66 \\
\hline $26-30$ & 3 & 4.0 \\
\hline $31-35$ & \multicolumn{1}{|l|}{} \\
\hline$>35$ & 15 & 20.0 \\
\hline Designation & 46 & 61.33 \\
\hline House Office & 14 & 18.66 \\
\hline Postgraduate & 66 & 88.0 \\
\hline Medical Officer & 9 & 12.0 \\
\hline Department & \multicolumn{1}{|l|}{} \\
\hline Gynecology\& Obstetrics & & \\
\hline Others &
\end{tabular}

\begin{tabular}{|c|c|c|}
\hline \multicolumn{3}{|c|}{$\begin{array}{l}\text { Have you been subjected to discriminate behavior by others which } \\
\text { eroded your professional confidence or self esteem }\end{array}$} \\
\hline Yes & 51 & 68.0 \\
\hline No & 22 & 32.0 \\
\hline \multicolumn{3}{|c|}{$\begin{array}{l}\text { If yes which of the following is the main source of undermining or } \\
\text { harassing? }\end{array}$} \\
\hline Administration & 9 & 12.0 \\
\hline Faculty & 26 & 34.66 \\
\hline Senior Colleagues & 32 & 42.66 \\
\hline Colleagues & 12 & 16.0 \\
\hline Paramedics & 15 & 20.0 \\
\hline Patients attendants & 22 & 32.0 \\
\hline \multicolumn{3}{|l|}{ Have you complained anyone about this? } \\
\hline Yes & 20 & 26.66 \\
\hline No & 40 & 53.33 \\
\hline \multicolumn{3}{|l|}{ If yes what was outcome } \\
\hline Satisfactory & 4 & 5.33 \\
\hline Unsatisfactory & 16 & 21.33 \\
\hline \multicolumn{3}{|l|}{ If no then what was the reason } \\
\hline Not sure how to complain & 11 & 14.66 \\
\hline Afraid of consequences & 17 & 22.66 \\
\hline Dealt with myself & 8 & 10.66 \\
\hline Not considered as serious & 12 & 16.0 \\
\hline It is worthless or of no benefit & 19 & 25.33 \\
\hline \multicolumn{3}{|l|}{ What were the ways of discriminate behavior? } \\
\hline Mocking/ scoffing/ making hurtful comments & 32 & 42.66 \\
\hline Discouragement on work done & 34 & 45.66 \\
\hline Giving too much assignments/ workload & 17 & 22.66 \\
\hline Exclusion from ward rounds/OT list & 14 & 18.66 \\
\hline Physical violence & 5 & 6.66 \\
\hline Verbal abuse & 10 & 16.0 \\
\hline \multicolumn{3}{|c|}{ Effects you noticed on your personality/ behavior? } \\
\hline Sadness & 31 & 41.33 \\
\hline Aggression & 24 & 32.0 \\
\hline Change in Sleep & 9 & 12.0 \\
\hline Suicidal thoughts & 5 & 6.66 \\
\hline Headache/ palpitations & 24 & 32.0 \\
\hline Loss of interest in activities & 31 & 41.33 \\
\hline Poor performance at work & 14 & 18.66 \\
\hline Lack of confidence & 35 & 46.66 \\
\hline Fear to go to work place & 15 & 20.0 \\
\hline Avoiding bullier & 22 & 29.33 \\
\hline Suicidal thoughts & 7 & 9.33 \\
\hline Thinking of quitting job/training & 13 & 17.33 \\
\hline Thinking of change of department & 22 & 29.33 \\
\hline Thinking of change of profession & 4 & 5.33 \\
\hline Did you get treatment from Psychiatrist? & 5 & 6.66 \\
\hline
\end{tabular}

\section{DISCUSSION}

Working place bullying is a major issue in medical services laborers in light of the fact that the functioning conditions are now distressing, requesting and sincerely debilitating. An amateurish conduct that influences the nobility at work environment will stay a question mark. It is an essential right of all to give them medical care administrations without dread of being a survivor of working environment harassing. The functioning day of workers ought not to initiate with stressing over being badgering, harassed or threatened in the work environment. Essentially, days at the work environment ought not to be loaded up with tormenting. It requires genuine concentration and need to build up a solid culture at the working environment. This will expect measures to forestall or diminish the frequency of working environment tormenting and proper disciplinary activities against capable people. Arrangement of a protected and positive workplace, where individuals flourish instead of upset, is the duty of each business. On the off chance that workers have a feeling of control, achievement and independence, it will result in advantage of the associations and improved soundness of workers. The 
harassing free workplace can expand the profitability of representatives which will prompt upgraded work execution. ${ }^{11-14}$

Bashir $^{15}$ in his survey of bullying among 108 health care professionals, he concludes that bullying leads to job dissatisfaction. Maaari ${ }^{16}$ in his cross sectional survey of 90 nurses at Civil Hospital Karachi, reported 35\% prevalence of bullying, physical violence $(46.7 \%)$, verbal harassment $(52.2 \%)$, bullying $(27.8 \%)$ and sexual harassment $(15.6 \%)$. A large portion of the savagery was endeavored by patients and their relatives and most of sexual abuse was witnessed by female nurses and majority of them were attempted by staff and co-workers while we conducted this cross sectional survey in sample size of 75 . We did not enquire about sexual harassment faced by lady doctors.

León-Pérez ${ }^{17}$ in his systemic review of 97 papers, more than 220,000 workers globally, reported alarming prevalence ratio in under developed countries such as those from South America, Asia, Pacific and Middle Asia regions.

Imran ${ }^{18}$ in his cross sectional survey of 654 doctors, reveals the $63 \%$ of prevalence, $50 \%$ of harassment is by consultants and teaching faculty with Persistent unjustified criticism in half of cases, among them $73 \%$ didn't complained to anyone. The physical violence against doctors and nurses reported 16.2 and 21.9 per 1,000, respectively in literature while in our study $6.66 \%$ cases reported. ${ }^{19}$ Indian study have reported that about half of junior doctors are bullied, the majority by consultants, while we observed $34 \%$ bullying by faculty. ${ }^{20}$

If we will find the routes of bullying behavior, we will find it in our culture. The youngsters are told to obey and follow elder ones. We cannot criticize on social norms and rules made by our ancestors. So this leads to high prevalence for this behavior. Conversation or looking for explanation isn't supported in the home and in schools; rather, it is viewed as inconsiderate and discourteous. These practices are regularly still seen as a component of the learning interaction and are not considered excessively brutal by most of guardians. The ideas of mentorship and guiding offices for specialists are as yet in their outset in Pakistan. The students have to be yes men, they can't argue with the orders whatever it is asked, and if one doesn't obey he is being victimized. And behind bullying by patients and attendants media has a key role. In country like Pakistan the journalism is at its worst situation. Electronic and print media have made a bad image of health care workers among society. Public always feel doctor and paramedic negligence in any case of complication.

\section{CONCLUSION}

Violence towards medical caretakers is expanding step by step and associations neglect to give the good preventive measures to shield the medical caretakers from brutality. Health care workers are actually and loudly mishandled by patients and their family individuals. Serving in safe and healthy surroundings is the basic right of every health care worker to take healthy decisions to give quality patient care so policy makers needs to take preventive measures to protect nurses from violent patients and their families.

\section{REFERENCES}

1. Lyons R, Tivey H, Ball C. Bullying at work: how to tackle it; a guide for MSF representatives and members. London: MSF; 1995.

2. Hills D, Joyce C. A review of research on the prevalence, antecedents, consequences and prevention of workplace aggression in clinical medical practice.Aggression Violent Behavior. 2013;18(5):554-69.

3. Imran N, Jawaid M, Haider II, Masood Z. Bullying of junior doctors in Pakistan: a cross-sectional survey. Singapore Med J 2010; 51(7):592.

4. Quine L. Workplace bullying in NHS community trust: staff questionnaire survey. BMJ 1999;318(7178):228-32.

5. Hoel H, Sparks K, Cooper CL. The cost of violence/stress at work and the benefits of a violence/stress-free working environment. Geneva: International Labour Organization 2001;81.

6. Paice E, Smith D. Bullying of trainee doctors is a patient safety issue. Clin Teacher 2009; 6(1):13-7.

7. Ahmer S, Yousafzai AW, Bhutto N, Alam S, Sarangzai AK, Bullying of medical students in Pakistan: a cross-sectional questionnaire survey. PLoS one 2008; 3(12): e3889.

8. Gadit AA, Mugford G. A pilot study of bullying and harassment among medical professionals in Pakistan, focussing on psychiatry: need for a medical ombudsman. $J$ Med Ethics 2008; 34(6):463-6.

9. Abbas MA, Fiala LA, Abdel Rahman AG, Fahim AE. Epidemiology of workplace violence against nursing staff in Ismailia Governorate, Egypt. J Egypt Public Health Assoc 2010; 85(1-2):29-43.

10. Cooper C, Swanson N. Workplace violence in the health sector. State of the art. Geneva: OrganizaciónInternacional de Trabajo, Organización Mundial de la Salud, Consejolnternacional de EnfermerasInternacional de Servicios Públicos. 2002.

11. Teoh KR, Hassard J, Cox T. Doctors' working conditions, wellbeing and hospital quality of care: A multilevel analysis. Safety Sci 2021; 135:105115.

12. O'donnell S, Macintosh J, Bulman D. The Support Needs of Men Who Are Bullied at Work. Int J Men's Health 2017;16(1).

13. Rosta J, Aasland OG. Perceived bullying among Norwegian doctors in 1993, 2004 and 2014-2015: A study based on cross-sectional and repeated surveys. BMJ Open 2018; 8(2):e018161.

14. Kumar NS, Munta K, Kumar JR, Rao SM, Dnyaneshwar M, A survey on workplace violence experienced by critical care physicians. Indian J Crit Care Med 2019; 23(7): 295.

15. Bashir A, Hanif R. Job satisfaction and burnout as outcome of workplace bullying among healthcare professionals. Rawal Med J 2018; 43(3):405-7.

16. Maaari $\mathrm{KH}$, Amjad $\mathrm{CM}$, Ansari Ml. Workplace violence towards nurses of intensive care areas and emergencies at civil hospital Karachi. J Univ Med Dent Coll 2017;8(4):36-45.

17. León-Pérez JM, Escartín J, Giorgi G. The presence of workplace bullying and harassment worldwide. Concepts Approaches Methods 2021:55-86.

18. Imran N, Jawaid M, Haider II, Masood Z. Bullying of junior doctors in Pakistan: a cross-sectional survey. Singapore Med J 2010;51(7):592

19. Chaplin C. Chapter Workplace bullying among healthcare workers. Workplace Bullying Occurrence in Alternative Organizational Milieus. 2017;39.

20. Bairy KL, Thirumalaikolundusubramanian P, Sivagnanam G, Saraswathi S, Sachidananda A, Shalini A. Bullying among trainee doctors in Southern India: a questionnaire study. J Postgrad Med 2007;53(2):87 